\title{
Japanese knotweed: impact on brownfield development and discussion on newly implemented innovative solutions
}

\author{
P. Mantzou \\ Wardell-Armstrong LLP, Consulting Engineers, Cardiff, Wales, UK
}

\begin{abstract}
Japanese knotweed (Polygonum cuspidatum) has become an important environmental issue prior to the development of a brownfield site. An invasive plant, it has the ability to spread once fragments are dispersed by natural means and human activity affecting the ecosystem and animal habitat as well as proposed costs and time-scales of any future development. Knotweed is a particular problem in the British Isles, having been introduced as a non-native species from Asia and is likely to spread further throughout Europe and beyond due to its nature of adjusting to different soil types and climates. The legal and financial implications in the UK are explored, as well as roles and responsibilities arising from knotweed presence. The methodologies used once knotweed has been identified are discussed and the liaison with relevant British government authorities and agencies clarified; efforts for the secure and applicable management of the knotweed are also discussed. The liabilities to the landowner or developer for treatment, including the role of environmental consultants to identify the best options for designing and managing the impact, are examined. The British experiences can be presented to a wider audience who may be encountering similar problems with site development. Current strategies used for the treatment of Japanese knotweed and their efficacies are highlighted and a phased, step-by-step approach in managing and treating the impact prior to the redevelopment of a site, is proposed. New innovations utilising geosynthetic technologies for more rapid, amicable redevelopment of Japanese knotweed affected sites, with less disruption and at lower costs, are described.
\end{abstract}

Keywords: knotweed, development issues, liabilities, treatment methods, eradication, phased approach, geosynthetics, SuDS. 


\section{Introduction}

Demand for housing, infrastructure and employment-providing land has meant an increasing reliance on brownfield sites and marginal land in Britain and elsewhere. Indeed, government regulations and laws prevent such development on 'greenfield' sites increasing demand and the need for solutions. Brownfield site development is an important aspect to regeneration of land and nature conservation. Numerous sites in the United Kingdom have been affected by the invasion of Japanese knotweed, causing many concerns to future developers and landowners as it may have a potential impact on the time-scale and cost of the proposed development.

A comprehensive and effective approach to control and eradicate this non-native species should be carried out and a well developed management operation that would be compliant with the relevant legislations that exist, thus minimising the size of impact, its disturbance and potential spread. The methodologies used should be efficient and environmentally friendly as well as cost-effective for the benefit of the developer/landowner and the environment at large.

\section{Background}

Japanese knotweed was introduced into the UK from Japan in 1825 as an ornamental garden plant and was broadly used for the stabilization of river banks (Bond \& Turner [1]). In the early $20^{\text {th }}$ Century, it had spread throughout south Wales where it became prevalent and subsequently escaped to become established in England (ibid). It is estimated to be present in $60 \%$ of UK development sites (Clyde \& Co [2]). It is located along rivers, railways, highways and waste tips where it has been negligently deposited, often illegally.

\subsection{Main characteristics}

Japanese knotweed, also known by the scientific name in current use Fallopia japonica belongs to the plant family Polygonaceae (the knotweeds), which derives from the Greek 'poly' meaning many and 'gony' meaning jointed (Japanese Knotweed Alliance [3]). This plant has large oval green leaves and a hollow stem, similar to bamboo. In springtime it produces red coloured shoots that can reach a height of $3 \mathrm{~m}$ by June. It grows rapidly $-20 \mathrm{~mm}$ per day in any type of soil, fertile or poor and its dense leaves create a large shed above other native species. In August, the plant flourishes and produces sterilised seeds whereas during the autumn and winter period the plant dies back leaving a dry deep brown stem (EA [4]). The knotweed has an intricate root (rhizome) network underground and depending on the ground conditions, it can extend $7 \mathrm{~m}$ around and $2-3 \mathrm{~m}$ beneath it. The spread of the plant is vegetative as it can be created and grow from its own pieces once transported by humans or watercourses (ibid). Due to the reason that it does not compete fairly with the country's native species, it has the ability to spread uncontrolled (Complete Weed Control [5]). Japanese knotweed is not considered to cause harm to human health given that it 
is not toxic but could have an effect on the ecosystem creating a poor habitat for animals by preventing the re-production of adjacent plants. Moreover, this invasive plant can cause extensive structural damage to buildings and infrastructure by emerging through bitumen and concrete, which also results in the destruction of important archaeological sites and flood defence structures. Erosion prevention and control along water courses are effectively reduced whilst the knotweed dies-back in winter; knotweed having effectively suffocated other established vegetation that would have provided root and soil-binding protection in the winter months. It has been estimated that $14,000 \mathrm{~kg} / \mathrm{ha}$ dry weight rhizome can be present at the upper $250 \mathrm{~mm}$ of topsoil on a site (Brock \& Wade [6]). It is worth noting that knotweed can be tolerant of highly acidic soil, topsoil contaminated with heavy metals and air pollution (Bond \& Turner [1]). The uncontrolled rapid spread of this invasive species has been affecting different countries worldwide causing implications on future developments, as in the UK. It has been found widespread across Europe from southern France/northern Italy to Norway and from California to Washington in the USA, Canada, New Zealand and Australia (Devon County Council [7]).

\subsection{Legal and financial implications}

The existence of government legislation for knotweed demonstrates the significance of this UK invasion and worldwide as it can cause delays in construction, create criminal and civil liabilities and can be costly to eradicate.

Regulations and legislation that cover the management and disposal of knotweed (two of which are generally enforced) are:

- Wildlife and Countryside Act 1981 (s.14) which creates an offence to spread knotweed and consequently causing it to grow in the wild and applies a heavy fine and imprisonment (EA [4]);

- Environment Protection Act (EPA 1990) Section 54 which states that Japanese knotweed contaminated material is likely to be classified as 'controlled waste' and its safe disposal should therefore be ensured by waste producers at a licensed landfill site according to the Environmental Protection (Duty of Care) Regulations 1991 without posing a risk to human health and the environment at large (Waste Management Licensing Regulations 1994 [4]). Failure to comply with the above provisions will be considered as an offence (ibid);

- Hazardous Waste Regulations 2005 (HWR 2005) which contain legal provisions regarding the handling and movement of hazardous waste, and Japanese knotweed material treated with certain herbicides can be classified as hazardous waste (ibid);

- The Control of Pesticides Regulations 1986, which create a liability for users who handle pesticides for the eradication of knotweed to protect human health and the environment in which they are applied to (ibid).

There can be cases of private or public nuisance from an inadvertent spread of the knotweed to neighbouring sites therefore affecting the landowner or the public in situations where there is evidence that the accused person may have 'foreseen' the spread (Clyde \& Co [2]). The presence of Japanese knotweed on a 
development site can add $10 \%$ to the total budget for its complete removal and legal disposal (Van Driesche et al [8]). Therefore, developers are advised to obtain legal guarantees that confirm the absence of the knotweed when purchasing a site otherwise depending on how profitable the development is likely to be they could either negotiate a reduction on the original price of the land or come to an agreement with the vendor to carry out a removal operation of the knotweed at his own cost prior to selling the property (EA [4]). A good example of the implications knotweed can cause to the time-scale and cost of a future development are the predominantly brownfield sites in east London hosting the 2012 Olympic Games. The presence of knotweed found spread across the sites has raised the budget to $£ 70 \mathrm{~m}$ (approx. $€ 100 \mathrm{~m}$ or $\$ 140 \mathrm{~m}$ ) for its eradication and currently remains the most important issue (Booth [9]).

\subsection{Roles and responsibilities}

There is no single organisation with responsibility for the control of invasive species in the UK, including Japanese knotweed. The responsibility for its control rests with the landowner or tenant of the land. The EA may carry out eradication surveys on land that it owns or flood defence structures that it maintains and being responsible for regulating waste, it can enforce prosecution if the law is not complied with (EA [4]). Treatment options will need to take account of controlled waters present on site and liaison with the EA should be undertaken as the use of an approved herbicide, in or near water, as well as burning of the plant requires their prior written approval. There is no legislation that requires the notification of relevant British Government authorities at the sighting of knotweed on a site, such as DEFRA (Department for Environment Food and Rural Affairs) and local authorities. Although, according to the Town and Country Planning Act (1990) s215 local authorities are empowered to require landowners to remediate land that has been infested by knotweed or undertake a remedial strategy themselves and recover the costs from the landowner by means of affecting the amenity of neighbouring and public areas (County Council of The City and Council of Cardiff [10]). In order to increase public awareness and to encourage the public to take actions to prevent the spread of knotweed there are documents and publications released by the EA and Local Authorities as well as financial support to public and private owners by County Councils. Government funding is also available to local authorities but only for areas of high priority. Also, the Welsh Assembly Government provides funds for biological research purposes in order to create a more sustainable and more effective treatment method.

These actions have increased the knowledge and responsiveness of land owners, tenants, developers, local authorities and consultants (ibid).

\subsection{Liaison and methodology used for managing Japanese knotweed on sites}

In order to ascertain that land to be given for future development is unaffected by the knotweed infestation or, if found to be infested by it to prevent its spread, a series of actions should be taken prior to the commencement of any works. 
Table 1: $\quad$ Actions and responsibilities prior to site redevelopment.

\begin{tabular}{|l|l|}
\hline Actions: & Responsibility: \\
\hline $\begin{array}{l}\text { Undertake a full site survey to locate and } \\
\text { record all areas of Japanese knotweed }\end{array}$ & $\begin{array}{l}\text { Ecology Surveyor in liaison with } \\
\text { environmental consultant and developer }\end{array}$ \\
\hline Seek advice once knotweed found on site & Developer \\
\hline $\begin{array}{l}\text { Develop a treatment management plan which } \\
\text { involves consultation and discussions with } \\
\text { relevant government authorities and the EA }\end{array}$ & Environmental Consultant \\
\hline $\begin{array}{l}\text { Determine timescale, cost and most } \\
\text { appropriate methodology for removal }\end{array}$ & $\begin{array}{l}\text { Environmental Consultant in liaison with } \\
\text { developer }\end{array}$ \\
\hline Implement eradication programme & $\begin{array}{l}\text { Qualified knotweed specialist contracted and } \\
\text { supervised by Environmental Consultant }\end{array}$ \\
\hline
\end{tabular}

Developers are advised to investigate the site for potential knotweed infestation at an early stage prior to its development in order to avoid excessive costs and potential prosecution. In the presence of watercourses within or adjacent to the site, the EA should be notified in order to gain their approval for the application of pesticides in or near water. Consultation should also be made, where appropriate, with adjacent landowners. The local authority will require a management plan to be implemented in order to grant planning permission. This will involve a survey by an ecology surveyor to be carried out to establish the presence/extent of infestation and most importantly, identify its potential source (Devon County Council [7]). The surveyor will identify the knotweed stands and the rate of spread including a record of other vegetation that is present on site that may be affected by its presence. The results are afterwards presented in the form of a report with photographic material and plans that show the extent. A Risk Assessment is then undertaken by the environmental consultant, based on the survey results along with a remediation strategy that presents the most suitable eradication options taking into account the time-scale of the proposed development and the immediate costs for dealing with the problem. Many sites are open to the public and therefore can be subject to material being imported, which may be contaminated. In this case, it is unlikely to identify the potential source. Most importantly, during the site inspection the presence of stands adjoining the site must also be noted in order to avoid any legal implications with neighbouring landowners. After identifying the best remedial options, a qualified contractor is appointed by the consultant in order to clear the site from the stands and secure its complete eradication. This work is managed efficiently and cost effectively under direct supervision, which ensures that regulations and site safety rules are being followed. The works and treatment should be monitored throughout the year and on-going survey work should be carried out at intervals to establish the success of the treatment or report any failure.

\subsection{Japanese knotweed management plan - role of consultants}

Treatment methods for the remediation of a knotweed infested site are provided by the environmental consultant to the developer in the form of a management plan that takes into consideration the findings from the ecological survey initially carried out on site. The selection of the most appropriate eradication solutions should balance the time-scale available and cost, and take into account the 
effectiveness and the surrounding environment where applied. The main aim of the management plan is to ensure that the development remains compliant with the relevant legislation for Japanese knotweed and is intended for use as guidance during the planning and operational phases of the works in order to prevent an accidental spread. The management plan is mainly developed in response to, and in accordance with "The Knotweed Code of Practice: Managing Japanese knotweed on Development Sites" (KCoP) published by the EA in 2006 [4]. The KCoP provides comprehensive guidance on techniques for managing risk on sites infested with knotweed and also provides details of control strategies and eradication methods. Once the appropriate agreed remediation method is selected, a suitably qualified operator of Japanese knotweed treatment is appointed by the environmental consultant to carry out the appropriate works.

\subsection{Eradication solutions, costs and effectiveness}

Early identification on a site can prove beneficial as it allows the developer to assess the main options available for management and disposal in terms of cost and time. The main treatment methods used for the complete eradication of knotweed, taking into consideration the available time and money, are as follows.

\subsubsection{Herbicide application treatment}

Used in situ and is the most cost-effective method. It enables the containment of an infestation without the possibility of it being spread to other areas. It can be effective although it does not completely destroy the infestation immediately. Herbicide application should be carried out when the plant is in its growing season (July to September) with the most important application in September as the maximum uptake of the chemical is achieved. However, it requires a minimum of nine spraying visits over three growing seasons in order to prove successful. It may not be considered as a suitable solution for big development sites where time can be more important than cost, nonetheless the plant should still be treated once with an appropriate herbicide if found in a flourishing state prior to other methods being used (EA [4]).

The approximate cost may vary from $£ 3-£ 8$ per $\mathrm{m}^{2}$ (approx. $€ 4-€ 11$ or $\$ 6-\$ 16 / \mathrm{m}^{2}$ ) in the UK. The EA's CoP states that there are a number of herbicides available for knotweed treatment, with Glyphosate and 2, 4-D Amine being the most suitable for preventing contamination to a watercourse, see Table 2 (ibid).

Table 2: $\quad$ Approved herbicides for use in the control of Japanese knotweed.

\begin{tabular}{|l|l|l|l|}
\hline Herbicide & Affects grasses? & $\begin{array}{l}\text { EA approved for use in } \\
\text { or near water? }\end{array}$ & Persistent? \\
\hline Glyphosate & Yes & Yes & No \\
\hline $2,4-D$ Amine & No & Yes & Up to 1 month \\
\hline Triclopyr & No & No & Up to 6 weeks \\
\hline Imazapic & Yes & No & Yes \\
\hline Picloram & No & No & Up to 2 years \\
\hline
\end{tabular}




\subsubsection{Excavation and spreading on site}

This method can be used only if an in situ treatment is not considered feasible and needs to be carried out in combination with spraying as it effectively reduces the time for chemical control. In order to avoid contamination of the soil, a non-persistent chemical such as Glyphosate ("Roundup Pro-Biactive"), which will not cause damage to neighbouring plants, should be applied. The excavation is to be carried out during winter when the plant dies back and at a depth of $3 \mathrm{~m}$ with a perimeter of $7-10 \mathrm{~m}$ from the margins of the stand within the site boundaries in order secure the complete removal of the infectious parts, i.e. rhizomes. The soil is sieved and placed on an uncontaminated part of the site that is to remain undisturbed for three growing seasons with continuous monitoring. The typical cost for this method of treatment would be $£ 15-£ 20 / \mathrm{m}^{3}$ and depends on the suitability of the site to hold and maintain a clear area for the treatment to take place.

\subsubsection{Excavation and removal from site}

After the infested material is removed from site through excavation, it is then transferred and disposed of at a suitably licensed landfill site and treated as controlled waste while being subject to various legal controls. This method of treatment can cost $£ 150-£ 350 / \mathrm{m}^{3}$. These costs include the transportation, tipping fees, tax, as well as backfilling, which may be imported from other sites or balanced from operations with clean soil.

\subsubsection{Excavation and burial on site}

This method follows the same methodology for excavation as in previous methods mentioned and would ideally be followed by an initial spraying operation to avoid a further distribution of the rhizome network once it has been disturbed. This would also assist in reducing the time period required for chemical control allowing the development of the site to take place at a short period of time. The excavation will be inspected for the presence of rhizome material through a watching-brief by a person competent in the identification of rhizome material. The excavation of the infested material is then placed in a suitable burial area on site, to a minimum depth of $5 \mathrm{~m}$. Once the material has been placed it is then covered by a high density polyethylene (HDPE) and/or suitable geotextile, prior to infilling. Due to the contaminated material being present on site a validation report may be required by the EA and the National House Builders Council (NHBC) to verify the location of the burial area and assess if any subsequent development is likely to be affected by it. The approximate cost for this method of eradication would be $£ 30-£ 40 / \mathrm{m}^{3}$. Careful design would mean sites could be developed quickly, often immediately, economically, with no delays.

\subsubsection{Other treatment methods}

Grazing, pulling and cutting of the knotweed stems are further options although they cannot provide complete eradication without the application of an appropriate herbicide. Another option is excavation, then very costly controlled incineration of the infested material, allowing almost immediate development. 


\subsection{Innovative solutions - geosynthetics/SuDS}

Synthetic permeable geotextile materials act as environmental barriers to prevent lateral and vertical soil penetration by knotweed rootlets and their subsequent gradual spread (Haghi [11]). Currently in the UK, geosynthetics have been widely considered where there is a requirement for an immediate remediation solution, while the competitive nature of the market calls for research trials to be carried out to increase their performance in terms of cost and sustainability (Resource \& Environmental Consultants Ltd [12]). Applications in the UK at present involve the use of advanced geotextile systems. These systems have been successfully applied to meet the requirements of the developer, by providing complete and safe eradication of the problem as well as huge savings in time and cost. More innovative geotextile design is currently underway as result of the rapidly increasing distribution of geosynthetic companies, which put in time and effort to eliminate any constraints faced during installation. There are two main types of geosynthetics for managing Japanese knotweed currently in the UK market depending on the type of application they are to be used for: permeable geotextiles, which allow filtration (i.e. $\operatorname{Root} X)$ and extremely low permeable geomembranes, which avert fine material (i.e. mud) from entering (i.e. DW300/700) (Haghi [11]). These allow the excavated infested material to be encapsulated within a designed trench. $\operatorname{Root} X$ is a physical and phytotoxic barrier that prevents water logging, due to its permeable nature, as well as soil instability, due to its ability to provide support to the soil thus avoiding erosion and the creation of soil flip planes. It may also be developed over and laid within landscaping and car park areas to prevent intrusion of knotweed rhizomes (REC Ltd [12]). In addition this root barrier also performs high resistivity to puncturing from sharp materials present in the ground. RootX consists of a copper foil sheet interbedded between a woven and nonwoven geotextile bonded together by needle punching allowing air/water ingress so as to allow surface water infiltration and prevent the build up of high water pressure below. The copper foil releases an inert chemical trace, which controls the penetration of rhizomes through the fabric while its low concentration, below relevant guidelines, does not cause a potential risk of contamination to humans and the environment (ibid). $D W 300$ is a root barrier that is used to 'wrap' the infested material in the form of envelopes or packages of geotextile creating a containment zone and is mainly used in open-space areas. This polyethylene membrane is of highly low permeability and is joined with double-sided adhesive tape or welded in situ. $D W 700$ is a low density polyethylene (LDPE) membrane, which can allow the fabrication of large pieces joined with double-sided adhesive tape while minimising site joining (ibid). Tuffline is a woven geosynthetic that is coated both sides with an impermeable LDPE coating and is suitable as a contemporary containment of infested material. Other geosynthetics include Lotrak (woven fabric), Typar (nonwoven fabric) and Terram (nonwoven fabric), which are applied on contaminated sites as they only work in unison with chemicals and therefore act as a storage medium and therefore cannot be considered as root 'barriers' (Rilem [13]). 
New geotextile systems are in development that would be even more effective, increasing the fabric's ability to withstand puncture and widening the rolls, for example, and incorporating features that make the system cheaper.

Sustainable urban drainage systems ("SuDS") are 'the way forward' for sustainable control of surface water run-off in urban environments. They allow surface water to be managed under natural processes while providing temporary rain storage during heavy storm events thus preventing the occurrence of flooding events and subsequent pollution (Wright \& Alkhaddar [14]). Prior to the installation of SuDS on a developing site infested by knotweed, consideration should be taken with regards to potential penetration and following damage of services from the spread of rhizomes, which tend to grow around them. Once knotweed has entered these sustainable drainage systems, it could affect the ability of water to drain away by causing overflowing conditions and the eventual spread of the knotweed roots to adjoined sites and remote areas through transportation by controlled waters with inevitable consequences. For that reason, the use of geotextiles for the encapsulation and protection of SuDS is also considered necessary prior to the placement of any infested material within the pit (Water-Lines Solutions Ltd [15]).

The main advantage, notwithstanding, of utilising SuDS on the redevelopment of brownfield sites affected by knotweed is that the systems themselves require careful design for their location and effectiveness followed by excavation and engineered backfill. Hence, during the design stages, locations for knotweed burial sites can be allowed for; during the SuDS construction, burial sites can be incorporated, reducing costs and timings. The same allowance can be made in areas that require landscaping and for noise bunds, aesthetic barriers, etc., which can all serve as knotweed burial sites once encapsulated in geotextile systems.

\subsection{Methodology and geotextile application}

Prior to the commencement of any excavation works carried out for the removal of knotweed infested material on site, the following considerations should be taken, in an engineered phased approach:

- Identification of most suitable location for the placement of infested material. This area should be $7-10 \mathrm{~m}$ away from any knotweed patches/stands. This 'distance' should be regularly checked with knotweed regulations and guidelines as it is likely to change;

- Selection of the most appropriate geotextile layer according to the site conditions (i.e. after checking the contaminative status of the site);

- Calculation of the total volume of soil to be excavated and re-used, if suitable for infilling;

- Clarification of drainage service locations prior to geotextile placement.

It is necessary for the excavation to be carried out during the winter period in order for the treatment to prove successful, as knotweed remains dormant. The on-site burial would ideally follow an initial spraying operation before and after the placement of the infested material to provide an additional control measure beneath the barrier system. The following methodology should be followed during on-site burial operations, again following a phased approach: 
- Inspection of excavated material to identify the total depth of rhizome spread;

- Supervision of careful knotweed transfer (ideally on geotextiles which can be re-used for the containment of knotweed material in the burial pit);

- Excavation of a trench at a minimum depth of $5 \mathrm{~m}$ along with a watching brief to inspect for the presence of rhizomes and, if drainage services are placed, the bottom of the trench is lined with a root barrier and sealed with joining tape (geomembrane) prior to the drainage installation to prevent puncturing as well as the blocking the open pores of the SuDS layer from fine sediments;

- Placement of an appropriate geotextile layer and insertion of the infested material, which is encapsulated within the designed trench. Checks carried out that the geotextile is installed correctly;

- On-going monitoring and surveys to be conducted to identify any potential re-growth that will need to be treated ("watching-brief");

- Design of systems should carefully assess the volume of rhizomes and soil that require treatment and the required burial pit dimensions to accommodate, allowing for bulking factors and compaction;

- Locations for knotweed burial can be around the periphery of sites or neighbouring sites, in landscape areas, under bunds/embankments (e.g. noise/aesthetic structures) and in open-spaces.

If the presence of knotweed on a large site delays the sale of land, or affects ownership, a compromise could be reached where the owner keeps possession of a smaller area of open-space/landscaping in which burial has been engineered, carrying out a watching-brief for a set number of months until the presence and/or spread of knotweed can be deemed to have stopped. The small parcel of land can then be handed to the purchaser. This may, therefore, allow redevelopment of large areas of land without delays.

\section{Conclusions}

Heading towards a sustainable future, the demand for redevelopment of brownfield sites is rapidly increasing whilst one preserves natural landscaped areas and improves the quality of urban areas by restoring lost habitats and reducing potential risks to human health and the surrounding environment. However, important issues that rise prior to the development of brownfield sites such as Japanese knotweed infestation, have created development constraints and financial implications to developers and landowners, who are obliged to comply with regulations enforced by the Government and relevant authorities in order to avoid actions which could result even in prosecution. Delays occur costing time and money.

Japanese knotweed has become a major concern in the British Isles as its uncontrolled spread is causing excessive costs to developers while increasing the timescale for development to take place.

The solution is careful and timely management of this invasive species to help delineate the problem, leading to its complete eradication. A phased approach is encouraged using experienced geo-environmental consultants. 
Newly developed innovative solutions, such as the design and application of geosynthetics can provide a rapid and cost-effective remediation solution to knotweed infested land and can speed up its redevelopment.

This sustainable and environmentally friendly treatment will also guarantee its complete removal preventing any future damage to structures and foundations, erosion and flooding events.

Placing such 'geosystems' within already designed-in landscaping and SuDS works could prove to be a boon, if engineered and supervised correctly.

\section{References}

[1] W. Bond \& R. Turner, The biology and non-chemical control of Japanese knotweed (Fallopia japonica (Houtt)), The Organic Organisation, pp. 1-3, 2006

[2] Clyde \& Co., international law firm, Managing Japanese Knotweed on development sites, pp. 6-10 Online. www.clydeco.com/knowledge/articles/ managining-japanese-knotweed-on-development-sites.html

[3] Japanese Knotweed Alliance. Online. www.cabi-bioscience.org/html/ japanese_knotweed_alliance.htm

[4] Environment Agency, Managing Japanese knotweed on development sitesThe knotweed code of practice, Environment Agency, pp. 6-19, 2006

[5] Complete Weed Control Ltd, Japanese Knotweed Online. www.completeweedcontrol.co.uk/invasiveweeds/japaneseknotweed.htm

[6] Brock J. and Wade M., Regeneration of Japanese Knotweed (Fallopia Japonica) from rhizome and stems. Observations from greenhouse trials, Proceedings $9^{\text {th }}$ International Symposium on the Biology of Weeds. Dijon, France. p. $85-94,1992$

[7] Devon Knotweed Forum, Devon County Council. Online. www.devon.gov.uk/contrast/japanese_knotweed.htm

[8] Van Driesche R, et al., Biological Control of Invasive Plants in the Eastern United States, USDA Forest Service Publication FHTET-2002-04, 413 p.

[9] Robert Booth, Knotweed sets Olympics $£ 70 \mathrm{~m}$ challenge, Times Online, 2007. Online www.timesonline.co.uk/tol/sport/london_2012/article15639 67.ece

[10] Environmental Scrutiny Committee, Short Scrutiny Japanese Knotweed, County Council of the City and County of Cardiff, pp. 7-15, 2006

[11] Dr. A. K. Haghi, Experimental analysis of geotextiles \& geofibres composites, WSEAS Press

[12] Resource \& Environmental Consultants Ltd, Geotextiles and Geosynthetics Online. www.recltd.co.uk/geotextiles.htm

[13] Rilem, Durability of Geotextiles, Chapman and Hall, pp. 187-205, 1988

[14] Dr. Amanda Wright \& Dr. Rafid Alkhaddar, Sustainable Urban Drainage Systems "The Way Forward", School of the Built Environment, pp. 3-9, 2005

[15] Water-Lines Solutions Ltd, Root Barriers Online. www.root-barriers.co.uk/ 